Res Publica. Revista de Historia de las Ideas Políticas

ISSN: $1576-4184$

http://dx.doi.org/10.5209/RPUB.56471

\title{
Conflictividad de las esferas, moralidad y política: afinidades entre Arendt y Weber
}

\author{
Ángel Prior Olmos*
}

Recibido: 19 de julio de 2016 / Aceptado: 10 de mayo de 2017

Resumen. El artículo plantea la existencia de serias afinidades entre Arendt y Weber a dos niveles: a) en su desarrollo evolutivo, desde el debate con Jaspers a propósito de la obra de Weber, hasta su etapa final, mostrándose los aspectos en que aparece la presencia weberiana; b) concretada en el problema de la relación entre moralidad y política, señalando las fuertes coincidencias entre ambos autores como puede apreciarse en sus respectivos análisis de la compasión y de los sentimientos morales, de la revolución francesa y en la valoración de Dostoievski y de Maquiavelo.

Palabras clave: Moralidad; política; esferas; modernidad; Arendt; Weber.

\section{[en] Conflict of Spheres, Morality and Politics: Affinities between Arendt and Weber}

\begin{abstract}
The article considers the existence of strong affinities between Arendt and Weber at two levels: a) in its evolutionary development, from the debate with Jaspers on Weber's work, to its final stage, showing the aspects with weberian presence; b) foused on the problem of the relationship between morality and politics, pointing out the great coincidences between both authors as can be seen in their respective analyzes of compassion and moral feelings, the French revolution and the valuation of Dostoyevski and Machiavelli.
\end{abstract}

Keywords: Morality; politics; spheres; modernity; Arendt; Weber.

Sumario: 1. El sueño de Jaspers: Arendt, Weber y Jaspers en compañía. 2. Diferenciación y conflictividad entre moralidad y política.

Cómo citar: Prior Olmos, Á (2017).Conflictividad de las esferas, moralidad y política: afinidades entre Arendt y Weber, en Res publica 20.2, 293-306.

La cuestión de las posibles afinidades entre Hannah Arendt y MaxWeber constituye un asunto en disputa aún no suficientemente tematizado, en el que poco a poco van surgiendo intervenciones ${ }^{1}$ que contribuyen a clarificar conceptos siempre

\footnotetext{
* Universidad de Murcia prior@um.es

1 Pueden verse los trabajos de T. Parvikko, “Committed to Think, Judge and Act: Hannah Arendt's Ideal Typical Approach to Human Faculties", en J. Hersen and D. Villa (eds.), The Judge and the Spectator. Hannah Arendt's Political Philosophy, Leven, Peaters, 1999, pp. 111-130; P. Baehr, "The Grammar of Prudence. Arendt, Jaspers, and the Appraisal of Max Weber", en S. E. Aschein (ed.), Hannah Arendt in Jerusalem, Berkeley, University of
} 
relevantes dada la entidad teórica de ambos pensadores, posiblemente en expresión de Kari Palonen los dos autores más importantes de la filosofía política alemana del siglo $\mathrm{XX}^{2}$.

En lo que sigue apoyamos la hipótesis, como rasgo de afinidad con el pensamiento de Weber, de una defensa de la pluralidad y autonomía de las esferas implícita en la obra de Arendt, al sostener una concepción autónoma de la política que emparenta a la autora no solo con Weber sino también con Carl Schmitt ${ }^{3}$. La resistencia a introducir la "cuestión social" como cuestión política da fe de esa posición, igualmente notable es su propuesta de separación entre pensamiento y política, que en cierta forma recoge la clásica dicotomía weberiana entre ciencia y política (las conexiones entre ciencia y producción acercarían a la ciencia con la política tal como se práctica modernamente con la dominación burocrática). Hay otras distinciones conceptuales que remiten a actividades vinculadas a necesidades específicas, como ocurre con las planteadas entre labor y trabajo, religión y política, filosofía y ciencia, entre las que se detectan en su cuerpo teórico.

Nuestro propósito es presentar uno de los aspectos de la coincidencia entre ambas concepciones, concretamente en el tratamiento, importante para los dos autores, de las relaciones entre moralidad y política. Pero antes es preciso indicar un mínimo marco de posiciones en que cabe entender la relación de Arendt con el tema Weber.

\section{El sueño de Jaspers: Arendt, Weber y Jaspers en compañía}

En su Correspondencia, concretamente en carta de 20 de abril de 1950, Jaspers informa a Arendt del siguiente sueño: "Anoche tuve un sueño sorprendente. Estábamos juntos en casa de Max Weber. Usted, Hannah, llegó tarde y fue recibida con alegría. La escalera se extendía a través de un barranco. El apartamento seguía siendo el mismo. Max Weber acababa de regresar de un viaje a través del mundo, había traído documentos políticos y obras de arte, sobre todo de Asia oriental. Nos ofreció una parte, los mejores a usted, ya que usted comprende la política mejor que yo"4. Y continúa su carta Jaspers refiriéndose a Los orígenes del totalitarismo:

Ahora la imagino corrigiendo las pruebas de su estupendo libro. ¿Y si, entre otras cosas, leyera otra vez lo que escribe Max Weber sobre el tipo ideal? - a fin de que, admitiendo que subsista todavía en su texto algo de la antigua visión histórica "totalizante", sustancializante, este resto también desapareciera. Pero quizás

California Press, 2001, pp. 306-324; T. Parvikko, “A Note on Max Weber Impact on Hannah Arendt's Thought", Max Weber Studies, 4.2, 2004, pp. 235-252; P. Baehr, "Personal Dilemma or Intellectual Influence? The Relationship between Hannah Arendt and Max Weber", en Max Weber Studies, 5.1 (2005), pp. 125-130; W. Thaa, "Democracia y crítica de la civilización en Max Weber y Hannah Arendt", en Revista Española de ciencia politica, 19, 2008, pp. 9-40; A. Kalyvas, Democracy and the Politics of the Extraordinary: Max Weber, Carl Schmitt, and Hannah Arendt, Cambridge, Cambridge University Press, 2008.

2 K. Palonen, "Imagining Max Weber's Reply to Hannah Arendt: Remarks on the Arendtian Critique of Representative Democracy", Constellations, vol. 15, n 1, 2008, p. 56.

3 Cf. M. P. Lara, The Disclosure of Politics, Struggles over the Semantics of Secularization, Nueva York, Columbia University Press, 2013.

4 H. Arendt y K. Jaspers, Correspondance 1926-1969, París, Payot, 1985, p. 221. 
sea inútil - aunque tengamos hoy de nuevo esa tendencia en la atmósfera creada por Hegel y Marx y que todavía no han abandonado Spengler y Toynbee, para saborear involuntariamente una migaja de la falsa grandeza vinculada a la historia después que le fuera arrebatada a Dios $^{5}$.

La respuesta de Arendt de 25 de junio fue muy escueta: "He leído mucho a Max Weber - a decir verdad, después de su sueño-. Me ha halagado, de manera tonta, hasta el punto de avergonzarme de mí misma. Sin embargo, esta maestría en la lucidez no está al alcance, al menos para mí. Le queda todavía algo de dogmático. (Eso sucede cuando los judíos se arriesgan a escribir historia)"6.

Como es sabido, después de la II $^{\mathrm{a}}$ Guerra Mundial, la amistad entre Arendt y Jaspers, y con ella el tema Weber, se consolidó extraordinariamente, de lo que dan fe tanto el volumen de la Correspondencia, como los textos de homenaje escritos por Arendt a lo largo de distintos avatares de la vida de Jaspers, es el caso de la "Dedicatoria" con motivo de la publicación de su primer libro en Alemana y a sugerencia de Jaspers (Sechs Essays, Heidelberg, 1948), la emotiva Laudatio a propósito de la concesión a su maestro en 1958 del Premio de la Paz de los Libreros alemanes (publicado como capítulo en Hombres en tiempos de oscuridad), o la alocución ante el fallecimiento de Jaspers en la ceremonia oficial en la Universidad de Basilea el 4 de marzo de 1969, en la que presenta a éste como la conciencia de Alemania durante un cuarto de siglo. También dice: "él sabía que ciudadanía y nacionalidad no tienen necesidad de coincidir, (pues era y permaneció siendo naturalmente un alemán) pero sabía también que la ciudadanía no es una simple formalidad"7.

Podemos distinguir dos grandes etapas en el debate de Arendt con Weber o con la herencia weberiana, precisamente ese momento del "Sueño de Jaspers" puede servir de criterio diferencial en tanto que, al situarse justo en la circunstancia de la publicación de Los orígenes del totalitarismo, marca una entrada en la fase madura de su pensamiento. Dejando aparte el debate indirecto que supone su reseña de Ideología y utopía de Carl Mannheim en 1930, que cabe interpretar como un debate "grosso modo" entre Filosofía y Sociología ${ }^{8}$ en el que desde luego la perspectiva arendtiana nunca fue sociológica, sobre todo en los sentidos ya más estrechos, ya excesivamente amplios de esa disciplina, con la que el propio Weber tuvo sus distanciamientos.

La primera manifestación del tema Weber en la obra de Arendt se encuentra en las cartas cruzadas con Jaspers entre el 1 y el 10 de enero de 1933, en las que se comenta el reciente envío de Jaspers de su libro sobre Weber, en respuesta a su vez por la recepción previa del ensayo de Arendt "Ilustración y judaísmo". En su carta de agra-

Ibidem, p. 221.

Ibidem, p. 223.

Ibidem, p. 901. Recuerda Arendt que, para Platón, tal vez dicho por el ateniense con no poca ironía, después de todo el terreno favorable para la filosofía era o el exilio, o cierta fragilidad, o bien un pequeño país insignificante donde uno pueda ser distinguido por sus acciones. Y deja esta interrogación: “¿Habría llegado Platón a filósofo si la situación de Atenas hubiera sido mejor?” (H. Arendt y K. Jaspers, op. cit., p. 901). Sobre la relación intelectual entre Arendt y Jaspers, cf. L. P. Hinchman and S. K. Hinchman, "Existenctialism Politized: Arendt Debt' to Jaspers”, en L. P. Hinchman and S. K. Hichmann (eds.), Hannah Arendt, Critical Essays, New York, 1994, pp. 143-178.

8 Cf. P. Baehr, "Philosophy, Sociology, and the Intelligentsia: Hannah Arendt's Encounter with Karl Mannheim and the Sociology of Knowledge”, Journal of Social Sciences and Philosophy, 19 (3), 2007, pp. 341-373; J. L. Villacañas, "La cuestión del espíritu: Weber en Arendt", en A. Prior, A. Rivero (eds.), Filosofia, historia y politica en Agnes Heller y Hannah Arendt, Murcia, Editum, 2015, pp. 19-36. 
decimiento, Arendt polemiza breve pero firmemente con la presentación de Weber como "el gran hombre alemán" y representante del "carácter alemán". En tanto que judía muestra sus distancias con la referencia al "sentido de la potencia mundial alemana" y de su misión en favor de la "civilización del futuro". Alemania es la lengua materna, la filosofía y la creación literaria. Esto lo puede y lo debe avalar, pero al tiempo debe guardar distancia. La resistencia de Arendt es en definitiva a identificar, como Jaspers pretende a propósito de Weber, la germanidad con la libertad ${ }^{10}$.

Jaspers, en su respuesta, muestra su sorpresa porque Arendt quiera "distinguirse en tanto que judía de lo alemán". Justifica el subtítulo de su libro (Weber. Deutsches Wesen im politischen Denken) como un compromiso con el editor, que afirmaba que Weber había devenido poco conocido, y acaba disculpándose pues en realidad la suya era "tal vez" la más desesperada tentativa de dar un contenido ético al concepto de lo "alemán", utilizando la figura de Weber"11. Arendt en su nueva carta reitera que se considera alemana en el sentido ya aclarado de lengua y cultura, sin que pueda ello asociarse además al destino político e histórico de Alemania, como sería el caso de Weber y reivindica de nuevo Jaspers ${ }^{12}$. Embarcada en el estudio sobre Rahel Varnhagen, en ese momento está planteándose, a nivel histórico, pero también implícitamente político, el problema de la asimilación o emancipación de los judíos en Alemania. La suerte de Alemania y la de los judíos están presentes en esta polémica en un momento en que ambas cuestiones se hacen cada vez más interdependientes.

Tras el debate de 1933, Arendt y Jaspers prácticamente no reanudaron su correspondencia (en medio quedan algunas cartas de Jaspers entre 1936 y 1938, años en los que intenta un encuentro con Arendt entonces exiliada en París) hasta 1945. En la década de los cuarenta hay dos grandes temas en los que puede mostrarse la presencia weberiana. En primer lugar, la autora reitera expresamente en su ensayo "La tradición oculta" la consideración del pueblo judío no solo como pueblo oprimido, sino también como pueblo paria, adoptando así la expresión de Max Weber: "La existencia política como pueblo se reflejaba en la condición socialmente paria, fuera de la sociedad, de sus individuos. Por eso los poetas, escritores y artistas judíos crearon la figura del paria, una nueva idea del ser humano muy importante para la humanidad moderna" 13 .

Esta figura del paria constituye para el historiador (perspectiva en la que se sitúa la propia Arendt y en la que gusta colocar también a Weber y a Marx) una tradición, bien que oculta ${ }^{14}$. Heinrich Heine, Chaplin, Kafka, forman parte de los nombres que la han tematizado. La autora enfatiza sobre todo el caso de Bernard Lazare, a quien presenta bajo la fórmula del "paria consciente"15, reivindicado por Tuija Parvikko ${ }^{16}$ como un ejemplo de su utilización del método de los tipos ideales.

\footnotetext{
H. Arendt y K. Jaspers, op. cit., pp. 50-51.

10 Arendt se refiere a que "no puede estar ni a favor ni en contra, cuando leo la magnífica frase de Max Weber diciendo que, por el restablecimiento de Alemania, se asociaría con el mismo diablo" (Ibidem, p. 51).

Ibidem, p. 52.

Ibidem, p. 54.

Arendt, "La tradición oculta", en La tradición oculta, Barcelona, Paidós, 2004, p. 50.

Ibidem, p. 50.

Ibidem, pp. 58-61.

T. Parvikko, “A Note on Max Weber Impact on Hannah Arendt's Thought”, en Max Weber Studies, 4.2, 2004.
} 
La cuestión de si Arendt ha seguido la metodología del tipo ideal constituye uno de los temas en disputa en la polémica que mantienen Peter Baehr ${ }^{17}$ y Tuija Parvikko acerca de la influencia de Weber en Arendt. Mientras Parvikko sostiene que el propio método de Arendt, en especial en los escritos de los años cuarenta, es weberiano y se encamina a proponer conceptos como paria o totalitarismo, como típico-ideales, Baehr niega esa identificación apelando a la ontología fenomenológica en que se inscribiría la obra arendtiana. A pesar de la discrepancia, cabe sugerir que no es incompatible la adopción de una ontología histórica con el posible uso de los tipos ideales, como puede derivarse de un importante coloquio sobre su obra celebrado en Toronto, en el que Arendt recibe preguntas tanto sobre si hace uso de alguna forma peculiar e idiosincrásica del significado de las palabras (Mcpherson), recoge rasgos escolásticos (por parte de M. McCarthy) o hegelianos (por A. Wellmer). La autora concede a Wellmer que seguro que habrá algún elemento de hegelianismo en su pensamiento, como consiente con McCarthy (que había indicado que Arendt ha creado un espacio con un área libre, ocupada por definiciones, su proceder consiste en diferenciar entre sí conceptos como labor y trabajo, fama y reputación, etc., lo que remite a un hábito medieval de pensamiento. Cada distinción sería como una casa pequeña, dando la sensación que todo el espacio que ha creado está efectivamente amueblado $\left.{ }^{18}\right)$. En cuanto a lo sugerido por Macpherson cree que no se trata de simple utilización idiosincrásica de las palabras: "En mi opinión una palabra tiene una relación con lo que denota, o con lo que es, mucho más fuerte que el mero uso que de ella hacemos. Es decir, usted atiende solamente al valor comunicativo de la palabra; yo me ocupo de su cualidad de apertura (revelación). Y esta cualidad tiene siempre naturalmente por supuesto un fondo histórico" ${ }^{19}$.

Ese fondo histórico es un punto de partida para Arendt, por ello, ante la pregunta sobre la distinción entre el teórico y el activista, matiza que no se trata de una incompatibilidad entre hombres sino entre actividades. Y a propósito de la observación de Weissman de que la autora sostiene una imagen idealizada de la Constitución americana, responde que hizo algo parecido a lo efectuado por Montesquieu con la Constitución inglesa, sobre la que construyó "un cierto tipo ideal". Y añade: “Actualmente todos procedemos así. De algún modo todos fabricamos lo que Max Weber llamó «tipos ideales». Esto es, pensamos un determinado conjunto de hechos históricos, discursos, y lo que tengamos, hasta que se convierte en un tipo consistente de regla" 20 .

El segundo tema sobre la posible posición weberiana tiene que ver con la comprensión misma del totalitarismo. En efecto, tras la publicación de Los orígenes del totalitarismo, en un contexto en que Arendt proyecta escribir su no logrado libro sobre los elementos totalitarios en el marxismo, mantiene diversas polémicas con

17 P. Baehr, "Personal Dilemma or Intellectual Influence? The Relationship between Hannah Arendt and Max Weber", en Max Weber Studies, 5.1 (2005), pp. 125-130.

18 H. Arendt, "Arendt sobre Arendt. Un debate sobre su pensamiento", en De la historia a la acción, Barcelona, Paidós, 1995, pp. 170-171. La autora asiente a la observación de McCarthy e indica, "es perfectamente cierto lo que dice usted acerca de las distinciones. Siempre que empiezo algo -nunca me gusta saber demasiado bien qué estoy haciendo-, lo hago diciendo "A y B no son lo mismo". Y esto por descontado, procede de Aristóteles. Y, para usted, de Tomás de Aquino, que hizo lo mismo" (Arendt, op.cit., p. 171).

19 Ibidem, p. 157. Para esta distinción entre valor comunicativo y valor revelador de las palabras, cf. H. Arendt, “Walter Benjamin, 1892-1940”, en Hombres en tiempos de oscuridad, Barcelona, Gedisa, 1992, pp. 178-191.

20 H. Arendt, "Arendt sobre Arendt. Un debate sobre su pensamiento", op. cit., pp. 162-163. 
Eric Voegelin, Waldemar Gurian, Jules Monnerot y otros destacados autores de la Sociología, la historiografía y el pensamiento político de los años cincuenta, en las que implícitamente se está hablando en el espíritu de Weber. Recogeremos dos referencias. Así en la discusión sobre Los orígenes del totalitarismo, Voegelin ha planteado por un lado como objeción, situándose en perspectiva weberiana, que Arendt, con su tono apasionado se ha apartado de la tradición de "sine ira et studio", es decir de la objetividad y neutralidad valorativa, pero por otro paradójicamente viene a acusar directa o indirectamente a la autora de sostener un liberalismo implícito (en el fondo esta dualidad valorativa es la misma que Voegelin adjudica a Weber en $L a$ nueva ciencia de la política, que justo su autor acaba de publicar). Arendt a juicio de su reseñista adoptaría una "actitud típicamente liberal, progresista y pragmatista ante los problemas filosóficos" ${ }^{\text {"21 }}$. Liberales y totalitarios comparten un suelo, el inmanentismo esencial que les une. Voegelin contrapone la que considera verdadera división ante la crisis contemporánea, no la existente entre liberales y totalitarismo, sino entre trascendentalistas religiosos y filosóficos, por un lado, e inmanentistas sectarios, liberales y totalitarios, por otro. "Todo esto suena a «pesadilla nihilista»", termina acusando Voegelin, en la que implícitamente incluye también a Arendt.

Arendt se defiende de ambas acusaciones. De la primera, la motivación y el tono emocional de su estudio y que la alejarían de la conveniente objetividad, ratificando esa motivación emocional precisamente no ajena sino adecuada al tema y a lo requerido para su comprensión ${ }^{22}$. Respecto a la equiparación entre liberalismo y totalitarismo como dos posiciones encuadradas dentro de una misma reacción ante la crisis espiritual, nos interesa subrayar que, en su respuesta, además de una cuestión metodológica importante, estará implícita la actitud ante la diferenciación de las esferas que también nos parece muy relevante en el presente contexto.

En la cuestión metodológica, Arendt distingue entre historia de las ideas e historia de los hechos o eventos, situándose ella misma en la segunda perspectiva, seguramente en compañía de Weber, también de Marx, frente al punto de vista de la historia de las ideas en que se coloca a Voegelin. Así, considera la secularización como un hecho del que le interesan especialmente sus consecuencias reales, por ejemplo, la separación entre iglesia y Estado como aspecto decisivo, frente a cualquier planteamiento propio de la historia de las ideas.

Esta última dimensión afecta al terreno donde Voegelin quiere llevar su propia caracterización del totalitarismo, en sus versiones nazi y comunista, bajo la forma de "religiones políticas". Ante la acusación de Voegelin de la existencia de un "credo inmanentista" común a filosofías y teorías políticas contemporáneas que pretenden o admiten la posibilidad de transformación de la naturaleza humana, Arendt identifica el núcleo de divergencia. El concepto de Voegelin de "Religión secular" y la interpretación de los movimientos totalitarios como una nueva forma de religión, se apoyan en la confusión entre dos esferas distintas, religión y política. No hay un sustituto de Dios en las ideologías totalitarias. Sin negar la existencia de cierta conexión entre ateísmo y totalitarismo, la respuesta al totalitarismo no puede ser volver a la religión y a la fe por motivos políticos. En el fondo, argumentos semi-tautológicos

21 E. Voegelin, "Acerca de "Los orígenes del totalitarismo"”, en E. Voegelin, H. Arendt, "Debate sobre el totalitarismo", Claves de la razón práctica, 124, 2002, p. 8.

22 En "El concepto de historia: antiguo o moderno", en Entre el pasado y el futuro, Barcelona, Península, 1996, pp. 49-100, vuelve a mostrar su distanciamiento con la pretensión metodológica de objetividad. 
fomentan "ideas" que hacen de Dios una función del hombre o de la sociedad. Esta funcionalización constituye el último y más peligroso estadio del ateísmo ${ }^{23}$.

La temática de las relaciones entre religión y política es abordada por otra parte en dos textos, uno de 1950, y otro de 1953. En el primero, "La religión y los intelectuales", en respuesta a una encuesta que le plantea la revista Partisan Review, concretamente sobre cuáles son las causas de la tendencia del "nuevo giro hacia la religión" que cabe observar entre intelectuales de ese momento ${ }^{24}$. Comentando la interpretación materialista de la religión, por la que todas las cosas tienen su causa, Arendt indica que "si se toma la causalidad como un principio válido, se acabará siempre en una «demostración» de la existencia de Dios". Y aquí remite de nuevo a Kant: "Como Kant mostró, la existencia de un hecho, nunca puede probarse por deducción lógica. Por lo mismo tampoco puede probarse su inexistencia. En términos científicos no podemos probar ni la existencia ni la inexistencia de Dios. Una «actitud científica» que crea poder hacer tales afirmaciones es la actitud de la superstición acrítica" 25 .

Puede apreciarse en estos comentarios una profunda afinidad de Arendt con Kant, pero también con Max Weber en lo que respecta, primero, a la distinción entre ciencia y religión; segundo, entre filosofía, religión y ciencia; por último, entre filosofía, ciencia, política y religión (es decir, cuatro actividades o esferas distintas), si se quiere matizar así. En "Religión y política", conferencia presentada en un debate en la Universidad de Harvard sobre si es básicamente religioso el combate entre el mundo libre y el comunismo (publicada en la revista Confluence en 1953), Arendt critica la idea de entender la pugna entre estos bloques en términos religiosos. Los defensores de esa tendencia tendían a entender el comunismo como una nueva "religión secular", a lo que el mundo occidental contrapondría un "sistema religioso" trascendente. Todo ello retrotrae al problema de la relación entre religión y política, en el que toma partido contra todo un amplio sector de intelectuales, historiadores y sociólogos, como Eric Voegelin, Jules Monnerot, su propio amigo Waldemar Gurian, etc., que interpretan las dos grandes ideologías totalitarias o específicamente el comunismo como un tipo de "religión política". En su análisis, la autora se desmarca de esa posición, insistiendo en las notas de cada esfera, la política y la religiosa, por lo que, más allá de las formas de autopresentación de las ideologías políticas, reincide en la naturaleza de las mismas, así como en lo propio de la religión como esfera específica. Arendt interpreta la aparición de la secularización en el sentido de que implica una separación entre la forma religiosa de vida y la política. El temor al infierno ha dejado de contar como factor que pueda estimular o impedir las acciones de la mayoría ${ }^{26}$.

23 H. Arendt, "Una réplica a Eric Voegelin”, Debate sobre el totalitarismo, Claves de la razón práctica, 124, 2002, p. 10 .

24 H. Arendt, "La religión y los intelectuales", en Ensayos de comprensión 1930-1954, Madrid, Caparrós, 2005, p. 279 .

25 Ibidem, p. 280.

26 H. Arendt, "Religión y política", en Ensayos de comprensión, op. cit., p. 465. "Ello parece inevitable si la secularidad del mundo implica la separación entre la esfera religiosa de vida y la política; en estas circunstancias la religión estaba forzada a perder su elemento primariamente político, igual que la vida pública estaba forzada a perder la sanción religiosa de una autoridad trascendente. Tal separación es un hecho, y tiene además señaladas ventajas para la gente religiosa como para la no religiosa. La historia moderna ha mostrado una y otra vez que las alianzas entre "el trono y el altar" sólo sirven para desacreditar a ambos..." (Ibidem, p. 466). 
Para terminar de perfilar el contexto teórico de afinidades entre Arendt y Weber debemos remitirnos a la propia caracterización de la modernidad tal y como se encuentra en el conjunto de La condición humana, especialmente en su capítulo final, "La vida activa y la edad moderna" ${ }^{27}$. Arendt se atiene a un diagnóstico de la modernidad definida por la paradoja del progreso, en sus dos tesis de la pérdida de sentido y pérdida de libertad. De nuevo su posición es de polémica con la historia de las ideas. No es básicamente la secularización como manifestación intelectual lo que le interesa, sino ante todo identificar los pilares básicos en que se ha movido la evolución del mundo moderno, con dos fenómenos fundamentales a destacar, la eclosión de la esfera de lo social, que viene a tener un papel semejante al del ascenso de la burocratización en la teoría weberiana, y la función decisiva jugada por la ciencia, como uno de los tres grandes acontecimientos que Arendt sitúa en la génesis de la modernidad: "el descubrimiento de América y la completa exploración de toda la Tierra; la Reforma, que al expropiar las posesiones eclesiásticas y monásticas inició el doble proceso de expropiación individual y acumulación de riqueza social, la invención del telescopio y el desarrollo de una nueva ciencia que considera la naturaleza de la Tierra desde el punto de vista del Universo". La comparación de los tres factores lleva a Arendt a una curiosa afirmación: "Si pudiéramos medir el impulso de la historia como medimos los procesos naturales, hallaríamos que lo que originariamente tuvo la menor repercusión, los primeros pasos del hombre hacia el descubrimiento del universo, ha ido constantemente incrementando su importancia y velocidad hasta eclipsar no sólo a la ampliación de la superficie de la Tierra, que tuvo su limitación final en las limitaciones del globo, sino también al aparentemente ilimitado proceso de acumulación económica" ${ }^{28}$. En cierta forma nos encontramos con una respuesta a la cuestión de cuál es el motivo culturalmente más importante: si como señaló Weber sería el capitalismo o, en un espíritu más heideggeriano, la ciencia y la técnica.

\section{Diferenciación y conflictividad entre moralidad y política}

Podemos considerar dos etapas bien diferenciadas en el tratamiento arendtiano de la relación entre política y moralidad. Una inicial, en los años cincuenta y principios de los sesenta, en la que la autora pondera los vínculos conflictivos entre ambos ámbitos y especialmente el potencial destructor de la primera cuando es utilizada en la esfera política. Un ulterior momento ocupa a partir de los debates en torno a Eichmann en Jerusalén y los juicios en Alemania contra criminales nazis. En ese contexto se centra en investigar el potencial político de la moralidad. Comentaremos aquí solo la primera.

27 H. Arendt, La condición humana, Barcelona, Paidós, 1993, pp. 277-349. En el contexto de la edición alemana de esta obra se produce la reacción de Jaspers al leer la nota a pie de página de Arendt en la que se permite hacer una breve alusión crítica a La ética protestante y el espíritu del capitalismo, indicando que ha sido corregida ligeramente en algunos detalles. La respuesta de Jaspers parece fuera de tono: "Esta obra de Weber muestra precisamente la sutileza científica que la gente tiene tanta dificultad en comprender" (...). "Este punto no carece de importancia para mí, pues se trata del sentido de la cientificidad que Max Weber sostenía. Sin duda Max Weber puede ser corregido en muchos puntos, si así se puede decir, y yo mismo le he objetado bastante mientras vivió. Pero en esta obra (al contrario de lo que sucedía con otros volúmenes de la sociología de las religiones), hay que poner de manifiesto el error, después de haberlo seguido paso a paso en su avance cognitivo" (H. Arendt, K. Jaspers, Correspondance 1926-1969, op. cit., p. 551).

28 H. Arendt, La condición humana, op. cit., p. 278. 
En el análisis de los conflictos entre política y moralidad encontramos uno de los temas en los que se pone de manifiesto la gran coincidencia de Arendt con Max Weber no solo sobre la autonomía, sino también sobre la beligerancia entre ellas, tal y como es representada en La politica como vocación.

Cabe destacar la diferencia de contexto socio-político desde el que cada autor hace su diagnóstico. En el caso de Arendt se trata de su preocupación por el mal político de nuestro tiempo caracterizado por el nazismo y el stalinismo. Enfatiza en su caso la conexión entre revolución y terror. Por su parte, Max Weber presenta sus reflexiones desde la situación de colapso político en que vive Alemania tras su derrota en la $\mathrm{I}^{\mathrm{a}}$ Guerra Mundial y el vislumbre (el futuro de Alemania y con él la propia civilización occidental está a su juicio en cuestión) de una "noche polar de una dureza y una oscuridad heladas, cualesquiera que sean los grupos que ahora triunfen" 29 .

Para Arendt, la respuesta a ese mal ha de ser política, no meramente moral. Hay un deber de resistir al mal político, cuya responsabilidad en cualquier caso es colectiva, como enfatiza en su escrito con ese título, "La responsabilidad colectiva". En Weber la réplica también es política y los peligros que observa son remitidos en gran medida a una ética de las convicciones caracterizada desde su renuncia a asumir la responsabilidad por las consecuencias, aunque en su caso el elemento decisivo depende de una cuestión de liderazgo no enfatizada en el caso de Arendt, que en el fondo estaría más próxima al giro individual pero también colectivo que imprime D. Bonhoeffer a su versión de la ética de la responsabilidad en su inacabada Ética y en las cartas desde la prisión ${ }^{30}$.

La ocasión intelectual específica del desarrollo de este problema en Arendt es su estudio de las revoluciones del siglo XVIII y de sus repercusiones en las del siglo $\mathrm{XX}$. En ese marco la autora analiza el uso como argumento político de expresiones de la moralidad, la bondad y los sentimientos morales, ponderando su matiz intrínsecamente conflictivo con la propia esfera política, así como su peligrosidad, mientras que Weber reincide en los aspectos nocivos de una pura ética de las convicciones en especial en situaciones de colapso político y de perspectiva revolucionaria, como se puede apreciar en su debate con pacifistas radicales o sindicalistas revolucionarios ${ }^{31}$.

Arendt resalta el carácter trágico y autodestructivo de la Revolución francesa ${ }^{32}$ (los dos autores comparten en realidad una visión trágica de la historia y de la política moderna, esforzándose sin embargo en buscar salidas en el interior de esa tragedia, hay en ambos un sentimiento de serenidad ante el abismo y en el fondo de gratitud hacia lo dado), al mostrar el planteamiento de la cuestión social como fuerza política, lo que después sería recogido en la conexión marxiana entre pobreza y explotación $^{33}$. El problema procede de su elaboración por Rousseau y su introducción

29 M. Weber, "La política como vocación”, en El político y el cientifico, Madrid, Alianza, 1972, p. 177.

30 Cf. L. Rasmussen, "The Ethics of responsible action", en J. W. de Gruchy (ed.), The Cambridge Companion to Dietrich Bonhoeffer, Cambridge, Cambridge University Press, 2002, pp. 206-225; D. Eslava García, "Colapso moral y responsabilidad en Dietrich Bonhoeffer", en A. Prior Olmos (ed.), Experiencia totalitaria, resistencia y testimonio de Bonhoeffer a Kertész, Murcia, Editum, 2015, pp. 41-96.

31 Sobre la referencia a Lukács, cf. el trabajo de J. L. Villacañas, "Max Weber and Agnes Heller. A complex reception", en A. Prior and A. Rivero, (eds.), Agnes Heller and Hannah Arendt. A Dialogue, Cambridge, Cambridge Scholars Publishing, pp. 34-49 (en prensa).

32 H. Arendt, Sobre la revolución, Madrid, Alianza, 1988, p. 83.

33 Ibidem, p. 63. "La idea de que la pobreza serviría para que los hombres rompieran los grilletes de la opresión, debido a que los pobres nada tienen que perder salvo sus cadenas, nos ha llegado a ser tan familiar a través de 
fáctica por Robespierre. Rousseau y Robespierre incluyen la agenda social y, podríamos añadir, la perspectiva moral en la Revolución francesa a través de sus análisis de la compasión y la piedad. La compasión entra en la escena de la revolución tras el fracaso de los girondinos: "Las experiencias reales que subyacen al desinterés y al «terror de la virtud» de Robespierre no pueden ser comprendidas si no se tiene en cuenta el papel crucial que la compasión ha desempeñado en las mentes y corazones de quienes prepararon la Revolución francesa y de quienes tomaron parte en ella. No ofrecía dudas para Robespierre que la única fuerza que podía y debía unir a las diferentes clases de la sociedad de una nación era la compasión de los que no sufrían por los malheureux, la compasión de las clases altas por el pueblo bajo"34.

Arendt interpreta la compasión como una pasión a la que corresponde el sentimiento de la piedad y pondera este último como la "perversión de la compasión" ${ }^{35}$, siendo su alternativa la solidaridad, que permite en tanto comunidad de intereses su acogida en la política ${ }^{36}$. Lo importante es que la piedad, "en cuanto resorte de la virtud, ha probado tener una mayor capacidad para la crueldad que la crueldad misma" ${ }^{37}$.

La autora realiza un estudio experiencial del poder destructivo de la introducción en política de aspectos morales como compasión, piedad, bondad, etc., a través del punto de vista, así lo indica, de la poesía ${ }^{38}$, recurriendo a las figuras del Gran Inquisidor de Dostoievski y a Moby Dick, de Herman Melville. Mientras que la "profundidad de este problema" a su juicio "apenas podría ser vislumbrada" por Rousseau o por Robespierre, lo que podemos aprender de Dostoievski o de Melville es que "la bondad absoluta es casi tan peligrosa como el mal absoluto, que no coincide con el desinterés... y que está más allá de la virtud"39.

Hay también una coincidencia entre Arendt y Weber en la referencia a Dostoievski. Para la primera, en El Gran Inquisidor se trata de una reflexión sobre las motivaciones que hay tras las palabras y hechos de los actores de la revolución francesa

las enseñanzas de Marx que tendemos a olvidar que era desconocida con anterioridad a la Revolución Francesa" (Ibidem, p. 17). Cf. los trabajos de M. Canovan, "Rousseau, and Human Plurality in Politics", en The Journal of Politics, vol. 45, n 2, mayo 1983, pp. 286-302; F. Fehér, "El paria y el ciudadano (sobre la teoría política de Arendt)", en A. Heller y F. Fehér, Politicas de la postmodernidad, Barcelona, Península, 1989, pp. 264-283; “Contra la metafísica de la cuestión social", en A. Heller y F. Fehér, Políticas de la postmodernidad, pp. 248-26; F. Fehér, La revolución congelada. Ensayo sobre el jacobinismo, Madrid, Siglo XXI, 1998; F. Fehér, "Freedom and the 'social question' (Hannah Arendt's Theory of the French Revolution)", Philosophy Social Criticism 12, 1987, pp. 1-30; S. Žižek, "Robespierre, o la "violencia divina” del terror”, en Virtud y terror. Slavoj Žižek presenta a Robespierre, Madrid, Akal, 2011, pp. 5-51. Acerca del uso de la tragedia como elemento común en Arendt y Weber, cf. el libro de R. Pirro, Hannah Arendt and the Politics of Tragedy, De Kalb: Il., Northern Illinois University Press, 2001.

34 H. Arendt, Sobre la revolución, op.cit., p. 81.

35 Ibidem, p. 89.

36 "La solidaridad es un principio que puede inspirar y guiar la acción, la compasión es una pasión, y la piedad es un sentimiento. La glorificación que de los pobres hizo Robespierre, su elegía del padecimiento como la causa de la virtud, fueron sentimentales en el sentido preciso de la palabra y en cuanto tales, bastante peligrosos, aún en el caso de que no fueran, como nos inclinamos a creer, un mero pretexto para su sed de poder" (Ibidem, p. 90).

37 Ibidem.

38 "Si queremos saber lo que haya podido significar la bondad absoluta en el curso de los asuntos humanos (en oposición al curso de los asuntos divinos, lo mejor que podemos hacer es volvernos hacia los poetas" (...) "Al menos podemos aprender que la bondad absoluta es casi tan peligrosa como el mal absoluto, que no coincide con el desinterés y que está más allá de la virtud" (Ibidem, 83).

39 Ibidem, p. 83. 
y contrasta la pasión muda de Jesús con la piedad elocuente del Inquisidor ${ }^{40}$. Por su parte, Weber alude a la figura del Gran Inquisidor para indicar que no es posible meter en política en el mismo saco las dos éticas, de igual modo que "no es posible decretar éticamente qué fines pueden santificar tales o cuales medios, cuando se quiere hacer alguna concesión a este principio" ${ }^{41}$. Lo curioso es que, a lo largo de este capítulo, Arendt no cite a Weber.

En coherencia con su énfasis en la importancia que en la modernidad ha adquirido el mal político y desde el potencial iluminador de la realidad contemporánea, Arendt confronta a los protagonistas de la Revolución francesa con este problema del mal y advierte una concepción sumamente errónea del mismo, concretamente en el recurso a la tesis de la bondad innata del hombre natural.: "Si la bondad del hombre en un estado de naturaleza había llegado a ser un axioma para Rousseau, eso se debió a que creía que la compasión constituía la reacción humana más natural frente a los padecimientos de los demás y, por tanto, la consideraba como el auténtico fundamento de toda verdadera relación humana «natural»" ${ }^{\prime 2}$.

Dado que ni Rousseau ni Robespierre podrían tener una experiencia directa de esa bondad innata, la autora apunta a que dedujeron su existencia de la corrupción de la sociedad. Weber por su parte, respecto a la diferencia entre ética de las convicciones y ética de la responsabilidad, contrasta dos figuras: por un lado, el caso del sindicalista partidario de esa ética de las convicciones, que no se siente responsable de las consecuencias negativas de su acción sino que responsabiliza al mundo, a la estupidez de los hombres o a la voluntad de Dios; por otro lado, el del partidario de una ética de la responsabilidad que "toma en cuenta todos los defectos del hombre medio. Como dice Fichte, no tiene ningún derecho a suponer que el hombre es bueno y perfecto y no se siente en situación de poder descargar sobre otros aquellas consecuencias de su acción que él pudo prever ${ }^{43}$.

Una manifestación del carácter erróneo de la concepción del mal que subyace a los planteamientos criticados, es la consideración del egoísmo y de la hipocresía como ejemplos de perversidad máxima ${ }^{44}$. La autora observa con detenimiento este fenómeno de la hipocresía y se pregunta por qué pudo ser considerado como una especie de crimen oculto. Estima natural que pudiera ser comprendido como el vicio de los vicios, ya que la integridad podría darse "bajo la capa de los demás vicios menos de éste". La hipocresía es el vicio a través del cual se presenta la corrupción ${ }^{45}$. La guerra contra ella además se puede justificar por la lucha contra la corte de Versalles, por la gran corrupción en ella imperante y su permanencia en los primeros años del cambio de régimen.

El problema a juicio de la autora, con su defensa de una perspectiva del presente inherente al proceder histórico, es que, como así lo mostraron las experiencias del terror totalitario, dicha hipocresía o el egoísmo mismo, no podrían ser considerados las mayores perversiones, además de que la concepción sobre la bondad innata del ser humano se tornaría completamente deficiente para un análisis de la realidad política. En este sentido, frente a lo que encontramos en la Revolución francesa, Arendt resal-

\footnotetext{
$40 \quad$ Ibidem, p. 86.

41 M. Weber, "La política como vocación", op. cit., p. 167.

42 H. Arendt, Sobre la revolución, op. cit., p. 81.

43 M. Weber, "La política como vocación”, op. cit., p. 164.

44 H. Arendt, Sobre la revolución, op.cit., p. 83.

45 Ibidem, p. 104.
} 
ta el realismo de los padres fundadores de la Revolución americana, que "contemplaron los defectos de la naturaleza humana" ${ }^{46}$. El peligro de la dinámica abierta por el recurso a la piedad y la caza del hipócrita es el carácter ilimitado de esta empresa. Cuando la Comuna de París indica en uno de sus manifiestos: "Par pitié, par amour, pour l'humanité, soyez inhumains", no se trata sino de una "corriente racionalización de la crueldad" y el tema es que "los sentimientos, a diferencia de la pasión y la razón, no tienen límites" ${ }^{\prime 4}$. Todo ello remite a la insensibilidad de los revolucionarios por la realidad en general, "y para las personas, en particular". De esta forma, la "fantástica irresponsabilidad y versatilidad" de la conducta de Rousseau, implícita en su "insensibilidad emotiva por la realidad" fue introducida por Robespierre en la lucha política de la Revolución ${ }^{48}$.

Weber, en su análisis de la política, se muestra también contrario a la hipótesis de la bondad natural del hombre, al señalar que quien actúa según una ética de la responsabilidad "toma en cuenta todos los defectos del hombre medio" y no tiene derecho "a suponer que el hombre es bueno y perfecto" 49 . En coherencia, la mesura ha de ser considerada como una de las virtudes más importantes de una ética política responsable ${ }^{50}$. Frente a esa moderación, para Arendt, los jacobinos en su búsqueda de una liberación de la necesidad y dada la dimensión de la miseria del pueblo y la piedad que ésta inspiraba, acogieron el principio "todo está permitido", que a partir de la inmensidad de los sentimientos del corazón llevará a la "liberación de una corriente de violencia sin límites" ${ }^{\prime}$.

Toda esta temática ha de ser relacionada con el lado conflictivo, peligroso y destructivo de la introducción en el ámbito de lo político de principios (como sentimientos, pasiones, ideas morales, etc.), pertenecientes a la esfera personal. En consecuencia, queremos sugerir una convergencia entre ambos autores en la idea de ordenaciones diferentes presente en Weber, y ya que cada ordenación está regida por un Dios o demonio particular, la mezcla de esas esferas no puede sino traducirse en una lucha de demonios particulares con consecuencias destructivas ${ }^{52}$. Esto no quiere decir que en el detalle Arendt argumente en términos de dioses o demonios, tampoco de valores últimos, pero sí conviene sobre las consecuencias destructivas de la mezcla.

Por otro lado, están las paradojas éticas que acompañan a la acción y que deben ser tenidas en cuenta por el hombre con vocación política. "Quien hace política pacta

46 Ibidem, p. 74. Para una contrastación entre ambas revoluciones, cf. F. Fehér, La revolución congelada. Ensayo sobre el jacobinismo, Madrid, Siglo XXI, 1998.

47 H. Arendt, Sobre la revolución, op.cit., p. 90.

48 Ibidem, p. 91. La relación entre violencia y terror ha sido tratada por D. Villa en "Political violence, and terror: Arendtian reflections", en Ethics \& Global Politics 3, vol. 1, 2008, p. 11.

49 M. Weber, "La política como vocación", op. cit., p. 164.

50 Mesura (Augenmass) es la cualidad psicológica decisiva del política y Weber entiende por tal la "capacidad para dejar que la realidad actúe sobre uno sin perder el recogimiento y la tranquilidad, es decir, para guardar la distancia con los hombres y las cosas..." (Ibidem, pp. 153-4). Sobre el tema, cf. B. E. Starr, "The Structure of Max Weber's Ethics of responsibility", en The Journal of Religions Ethics 3, vol. 27, 1999, pp. 407-434.

51 H. Arendt, Sobre la revolución, op.cit., p. 93.

52 Las ordenaciones diferentes son acentuadas por Weber en la conferencia sobre la política como vocación, por ejemplo, indica que "las distintas éticas religiosas se han acomodado de diferente modo al hecho de que vivimos insertos en ordenaciones vitales distintas, gobernadas por leyes distintas entre sí" (M. Weber, "La política como vocación", op. cit., p. 168). 
con los poderes diabólicos que acechan en torno a todo poder" ${ }^{33}$. Weber muestra su sorpresa y considera "políticamente hablando" que "quien no ve esto es un niño", a propósito de lo expresado por su colega Forster, que insiste en la "simple tesis de que de lo bueno sólo puede resultar el bien y de lo malo, sólo el mal. No solamente el curso de la historia universal sino también el examen imparcial de la experiencia cotidiana, nos está mostrando lo contrario" 54 , y negarse a admitirlo en el fondo procede de no soportar la irracionalidad ética del mundo y desconocer los impulsos originales de los que surge el poder de la teodicea, a saber, cómo es posible aceptar "este mundo irreal del sufrimiento inmerecido, la injusticia impune y la estupidez irremediable". En las propias palabras de Weber: "Este problema de la irracionalidad del mundo ha sido la fuerza que ha impulsado todo desarrollo religioso" 55 .

Al enfatizar los principios éticos específicos de la política, Arendt y Weber coinciden en la referencia a Maquiavelo como el primer autor que ya tuvo conciencia de estos conflictos. Weber indica, a propósito de la lucha entre el papado y Florencia, cómo "el genio o demonio de la política vive en tensión íntima con el dios del amor, incluido el dios cristiano" en un combate sin solución, y por ello Maquiavelo "pone en boca de uno de sus héroes la alabanza de aquellos que colocan la grandeza de la patria por encima de la salvación de sus almas" ${ }^{\prime 6}$. Y Arendt, en su propio contexto, hablando del carácter políticamente demoledor de la bondad, matiza: "Quizá nadie ha comprendido tan agudamente como Maquiavelo esta ruinosa cualidad de ser bueno, quien, en un famoso párrafo, se atrevió a enseñar a los hombres «cómo no ser buenos»" $" 57$, convergiendo en el detalle Arendt con Weber al precisar que el criterio de Maquiavelo era la gloria, aunque para la primera no es tanto la salvación del alma lo que se le opone, sino en concreto la bondad ${ }^{58}$.

Más allá de su aspecto dañino, al final Arendt y Weber vuelven a mostrar su sintonía en atender a lo específico de la moralidad, en un tratamiento radical y restrictivo de la misma. En el caso de Weber, en el trasfondo de toda la conferencia sobre la política y en otros textos cruciales (como la introducción o el excurso a los Ensayos sobre sociología de la religión), estaría el recurso a una ética de la bondad o del amor entendida como una ética absoluta, para la cual, si bien declara no sentirse atraído, considera que quien no esté dispuesto a aceptar la parte de culpa inherente a una ética de la responsabilidad, a asumir la carga del mundo tal y como es, y de las consecuencias "inmorales" de la acción política, lo que recomienda es ocuparse "lisa y llanamente de la fraternidad de hombre a hombre y dedicarse simplemente a su trabajo cotidiano" 59 .

Arendt por su parte en La condición humana trata el asunto en el parágrafo 10 del capítulo II de dicha obra, titulado "El lugar de las actividades humanas", momento privilegiado de su categorización de la bondad, el tipo de experiencia en que se ma-

Ibidem, p. 173.

Ibidem, p. 167.

55 Ibidem, p. 167-168. Sobre la irracionalidad ética del mundo y el conflicto entre las dos éticas, cf. N. Gane, "Max Weber on the Ethical Irrationality of Political Leadership", en Sociology, 31, 3, August 1997, pp. 549-564, y

Z. Slavnic, "The Ultimate Ends of Political Responsibility, or a Responsible Interpretation of Max Weber", en Themes, $\mathrm{n}^{\mathrm{o}} 25,2004$.

56 M. Weber, "La política como vocación”, op. cit., p. 174.

57 H. Arendt, La condición humana, op. cit., p. 82.

58 Ibidem, p. 82.

59 M. Weber, "La política como vocación”, op. cit., p. 178. 
nifiesta y las implicaciones y contradicciones con la política que le son inherentes. La autora vincula el conocimiento en nuestra civilización de "la bondad en sentido absoluto, diferenciada de «lo bueno para» o lo «excelente» de la antigüedad griega y romana", "con el auge del cristianismo" ${ }^{60}$. Anticipando los puntos de vista expuestos en Sobre la revolución, conduce sus planteamientos a la tesis de que la bondad "como consistente forma de vida, no solo es imposible dentro de los confines de la esfera política, sino que incluso es destructiva" ${ }^{\circ 1}$. Por último, las posibilidades de la bondad para el ejercicio de una ética de resistencia en situaciones de colapso moral, serían contempladas en "Algunas cuestiones de filosofía moral" y en el libro II de La vida del espiritu.

60 H. Arendt, La condición humana, op. cit., p. 79.

61 Ibidem., p. 82. 